\title{
Synthesis of Iron Oxide Nanoparticle Functionalized Activated Carbon and Its Applications in Arsenic Adsorption
}

\author{
Hoang Thu Ha $\mathbb{D}^{1},{ }^{1}$ Pham Tuan Phong $\mathbb{D}^{2}$ and Tran Dinh Minh $\mathbb{D}^{1}$ \\ ${ }^{1}$ VNU University of Education, Vietnam National University, Cau Giay, Hanoi 100000, Vietnam \\ ${ }^{2}$ High School for Gifted Students (HSGS), VNU University of Science, Hanoi 100000, Vietnam \\ Correspondence should be addressed to Tran Dinh Minh; minhtd.hes@vnu.edu.vn
}

Received 28 November 2020; Revised 5 February 2021; Accepted 13 April 2021; Published 28 April 2021

Academic Editor: Krishna Verma

Copyright ( 2021 Hoang Thu Ha et al. This is an open access article distributed under the Creative Commons Attribution License, which permits unrestricted use, distribution, and reproduction in any medium, provided the original work is properly cited.

This work reveals the $\mathrm{As}(\mathrm{V})$ adsorption behaviors onto iron oxide (Fe3O4) nanoparticles modified activated carbon (AC), originally developed from biochar (BC), as a green adsorbent denoted by FAC. Since FAC has abundant surface functional groups and a desired porous structure that is favorable for the removal of $\mathrm{As}(\mathrm{V})$ in contaminated water, FAC has greatly enhanced the $\mathrm{As}(\mathrm{V})$ adsorption capacity of the original BC. Various methods were employed to characterize the FAC characteristics and adsorption mechanism, including $\mathrm{pH}_{\mathrm{pzc}}$ determination, BET specific surface area, elemental analysis (EA), and scanning electron microscopy (SEM). Results show that the AC surface was successfully modified by iron oxide nanoparticles, enhancing the porosity and specific surface area of original adsorbent. Batch adsorption tests indicated a well-fitted Langmuir model and pseudosecond-order model for $\mathrm{As}(\mathrm{V})$ adsorption. Additionally, the highest adsorption capacity $\left(Q_{\max }=32.57 \mathrm{mg} / \mathrm{g}\right)$ by FAC was higher than previously reported literature reviews. Until now, no article was conducted to research the effect of carbon surface chemistry and texture on As removal from waters. It is required to obtain a rational view of optimal conditions to remove As from contaminated water.

\section{Introduction}

Recently, in many developing countries such as Laos, Vietnam, and Cambodia, Arsenic (As) has been detected as an emerging contaminant due to its detection in water environment and negative effects on human health, and natural ecosystem. As $(\mathrm{V})$ is among abundant elements on Earth and participates in various natural processes as well as human activities. It has been identified as the king of poisons and the deadliest toxicity in the world, negatively affecting human health more than any other chemical elements in the periodic table $[1,2]$. It was first discovered in the $8^{\text {th }}$ century by Jabir, an Arabian, in the form of a creative white arsenic or arsenic trioxide $\left(\mathrm{As}_{2} \mathrm{O}_{3}\right)$. At that time, it was named product of Jabir, an odorless, tasteless toxic that could kill people very quickly without leaving any trace in the human body $[3,4]$. The median lethal dose of $\operatorname{LD}_{50}(50 \%$ of laboratory tested animals have died) of arsenic is $763 \mathrm{mg}$ per kilogram of body weight (via diet) and $13 \mathrm{mg}$ per kilogram of body weight (via injection) [5]. However, arsenic is still not as toxic as its oxidizing compounds, such as arsenic trioxide $\left(\mathrm{As}_{2} \mathrm{O}_{3}\right) . \mathrm{As}_{2} \mathrm{O}_{3}$ is around 500 times more deadly than elemental arsenic, similarly to dioxin. Arsenic is a naturally occurring component of the earth's crust, which is discharged into aquifers when water flows through the underlying sedimentary rock layers $[6,7]$. Thus, the highest risk of As(V) pollution from drinking water in drilled wells and village drills is lower than that in lakes or streams. As and its compounds, once they penetrate into the livings, cannot be rejected through biochemical cycles and accumulated in body, causing serious impacts [8]. At present, it is estimated that more than 150 million people in worldwide have been affected by increasingly concentration of As in drinking water [9]. The most influenced areas that have been reported include Mekong delta (Vietnam, Cambodia), Hetao river (Mongolia), Duero Cenozoic Basin (Spain), and Tulare Lake (USA). Radical actions need to be done for treatment of As and its derivatives in water environment. 
Iron oxide nanoparticles are metal oxide particles coming in the size range of approximately 10 to $100 \mathrm{~nm}$. It is clearly proved that nanoscale $\mathrm{Fe}_{3} \mathrm{O}_{4}$ particles possess high magnetic nature, high surface area, electrical and thermal conductivity, and also excellent dimensional stability. The applications of iron oxide nanoparticles lie on multiple fields such as data storage and resonance imaging, alloy and catalyst industry, drug delivery, and medical treatment [10]. Currently, the iron oxide nanoparticles are among favorable choice for treatment of multiple ground contaminants, for example, polychlorinated biphenyls (PCBs), chlorinated organic solvents, and organochlorine pesticides. This feature is due to the fact that iron oxide nanoparticles are easily transportable through ground water, non-toxic to environment and human health, and thus can be injected into the polluted area and left to stay there for long periods of time [11]. The researchers demonstrated that aluminium and iron oxides are the most commonly applied materials for As removal $[12,13]$. Dao et al. concluded that the nanocomposite of metal oxides (mixed oxide between iron and $\mathrm{Mn}_{2} \mathrm{O}_{3}$ ) with functionalized polymer of polyvinyl alcohol (PVA) are desired for the removal of As [14-16]. MamindyPajany et al. investigated that the arsenic adsorption using activated iron minerals of iron such as goethite and haematite increased at acidic $\mathrm{pH}$ values [17]. Pena et al. observed that nanocrystal $\mathrm{TiO}_{2}$ powders displayed a great adsorption efficiency for As [18]. Currently, in Vietnam there are so many treatment facilities employed and applied to remove As in waters, especially in several cities such as $\mathrm{Ha} \mathrm{Nam}$, Thai Binh, Lam Dong, Ho Chi Minh, and Hanoi. According to the recent literature reviews, it shows that groundwater in these regions is contaminated with As at a high level, exceeding the allowed standard from 8 to 18 times. Therefore, the issue of clean water to ensure hygiene for people in Vietnam is not guaranteed [19].

In recent years, growing significance is contributed to the synthesis of biochar (BC) from biomass and wood waste (w.w), as an increase in research studies and publications can be found. It is a high-carbon source, fine-grained residue generated from the pyrolysis of agricultural and organic materials such as corncob, husk, stalk, potato, rice, and wheat straw, under the absence of oxygen. Interestingly, because of carbonization, BC had excellent physical (high surface area, porous morphology) and chemical composition (surface functional groups) associated with adsorptive capability. In comparison with currently commercial activated carbon (AC), $\mathrm{BC}$ has less defects, lower fabrication cost, and higher reusability. Furthermore, BC adsorption activity can be facilely enhanced by chemical activation or thermal modification. One of the current approaches is to modify carbon-based materials with active polymers by increasing the surface functional groups, resulting in improving $\mathrm{As}(\mathrm{V})$ adsorption efficiency such as [3-(2-aminoethylamino)propyl]trimethoxysilane (AEAPTMS) [15], (3Aminopropyl)triethoxysilane (APTES) [20], and PVA [16]. The amino silane molecules of AEAPTMS are distributed on $\mathrm{Fe}_{3} \mathrm{O}_{4}$ magnetic nanoparticles via oxygen bridge. This is the reaction commonly used to attach organic functional groups to the surface of materials containing - $\mathrm{OH}$ groups on their surface [21]. Amine groups on the surface of $\mathrm{Fe}_{3} \mathrm{O}_{4}$ will serve as the basis for the fixation of surface complexes with $\mathrm{As}(\mathrm{V})$ in the next process. The advantage of magnetic materials is that both adsorbent and adsorbate are able to separate from the reaction system mixture easily by using a magnet. In addition, our materials are recoverable and reusable by depositing $\mathrm{Fe}_{3} \mathrm{O}_{4}$ on the surface of original biochar (OBC), thereby contributing to green chemistry-oriented treatment, and environmentally sustainable.

\section{Methodology}

\subsection{Synthesis of Adsorbents $O B C$ and FAC}

2.1.1. The Production of $O B C$. The technology to generate $\mathrm{BC}$ could be based on various pyrolysis platforms, which might be dated to thousands of years ago. In this study, the process of $\mathrm{BC}$ pyrolysis through the thermochemical route was derived from urban w.w at a high temperature range in the absence of oxygen. The collected w.w content is approximated in Table 1. As can be seen in Table 1, the w.w in type III obtained the highest mass fraction (wt\%) of wood residues; therefore, it might be selected for further procedure. The carbon-rich source was used as the feedstock for the generation of OBC. Briefly, the w.w was collected in urban w.w in Hanoi, Vietnam, and then polysized in a quartz bowl inside a tubular furnace at a heating rate of $5^{\circ} \mathrm{C} / \mathrm{min}$, in ultra-high purity nitrogen (UHPN) atmosphere at a fixed temperature $500^{\circ} \mathrm{C}$ for $3 \mathrm{~h}$. OBC was collected from the furnace and cooled to the room temperature (RT). After that, $\mathrm{OBC}$ was reduced to the extremely fine nanoparticle size, homogeneous mixture and mesoporous structure, and almost uniform distribution by using planetary ball-milling (or mechanical milling) process.

2.1.2. Synthetic Route of Preparation of $\mathrm{Fe}_{3} \mathrm{O}_{4}$. Iron oxide nanoparticles were fabricated according to the previously published literatures with a small modification. In the first step, the following pure salts $\mathrm{FeCl}_{3} \cdot 6 \mathrm{H}_{2} \mathrm{O}$ and $\mathrm{FeCl}_{2} \cdot 4 \mathrm{H}_{2} \mathrm{O}$ with mole ratio of $1: 2$ were dissolved in ethanol $(\mathrm{EtOH})$ at $95^{\circ} \mathrm{C}$, and then the $\mathrm{pH}$ of suspension was stably adjusted up to 11 by gradually adding $\mathrm{NaOH}$ solution with the help of constant magnetic stirring for $40 \mathrm{~min}$. The final solid was magnetically collected and then washed with deionized water (DI water) and $\mathrm{EtOH}$ in order to eliminate the unexpected impurity. Next, the solid was dried at $105^{\circ} \mathrm{C}$ in vacuum for further experiments.

2.1.3. Synthesis of FAC. $\mathrm{Fe}_{3} \mathrm{O}_{4}$ nanoparticles and $\mathrm{OBC}$ were prepared as the starting materials via polymer-dispersible. In brief, about $1 \mathrm{~g}$ of $\mathrm{Fe}_{3} \mathrm{O}_{4}, 5 \mathrm{~g}$ of $\mathrm{OBC}$, and $300 \mathrm{~mL} \mathrm{EtOH}$ were suspended in a round bottomed flask. It was sonicated at $65^{\circ} \mathrm{C}$ for $30 \mathrm{~min}$, until the nanoparticles were dispersed completely. $15 \mathrm{~mL}$ AEAPTMS solution (technical grade, $\geq 97 \%$ ) was drop-wise added to the flask under vigorous agitation. The mixture was then collected by a magnet and designated as FAC. About $1.5 \mathrm{~g}$ of FAC was carried out via thermal treatment was carried out in a quartz boat inside a 
TABle 1: Proximate analysis of urban w.w compositions and properties.

\begin{tabular}{lccc}
\hline Content & w.w type I & w.w. type II & w.w. type III \\
\hline Moisture (wt\%) & 11.8 & 12.4 & 13.5 \\
Volatile (wt\%) & 85.4 & 77.6 & 83.9 \\
Ash content (wt\%) & 2.3 & 3.1 & 3.7 \\
Other waste matters (\%) & 1.2 & 1.1 & 2.0 \\
Wood residues (\%) & 85.6 & 87.9 & 88.5 \\
\hline
\end{tabular}

horizontal tubular furnace, and heated to the favorable temperature of $600^{\circ} \mathrm{C}$ for $2 \mathrm{~h}$. FAC was then cooled down over night in UHPN atmosphere. After the heat treatment, the final FAC was stored in a desiccator for further use and $\mathrm{As}(\mathrm{V})$ adsorption tests.

2.2. Material Characterizations. The BET specific surface area, total pore volume (TPV), and average pore diameter (APD) of OBC and FAC were examined by a BrunauerEmmett-Teller (BET) analysis (NOVA, 2200E series), including total pore volume (TPV) and average porous diameter (APD). Surface science of the as-synthesized material was observed using field emission-scanning electron microscope (FE-SEM; JSM-F100). The main inorganic elemental analysis of materials was calculated by $\mathrm{x}$-ray fluorescence (XRF analyzer, Perkin-Elmer). The determination of the point of zero charge $\left(\mathrm{pH}_{\mathrm{pzc}}\right)$ of each sample was conducted following the previous work [22]. Briefly, the $\mathrm{pH}$ of the solution in system was adjusted by adding either diluted $\mathrm{HCl}$ or $\mathrm{NaOH}$ solutions. A series of $50 \mathrm{~mL}$ of $\mathrm{NaCl}$ $0.01 \mathrm{M}$ was prepared in pre-boiled water in order to prevent $\mathrm{CO}_{2}$ dissolution, and then, $0.1 \mathrm{mg}$ of samples was added to $100 \mathrm{~mL}$ of I water with varying $\mathrm{pH}$ from 2 to 12 and constantly stirring for $24 \mathrm{~h}$ until the $\mathrm{pH}$ values reached stable. The final $\mathrm{pH}$ of the solution was plotted against initial $\mathrm{pH}$ of the solution. The initial and final concentrations of $\mathrm{As}(\mathrm{V})$ were measured by using inductively coupled plasma mass spectrometry (ICP-MS, model Agilent, 7500-Series, Japan).

2.3. Chemicals and Agents. All agents and $\mathrm{As}(\mathrm{V})$ standard solutions were of analytical grade and purchased from Sigma-Aldrich, and then stepwise diluted with DI water to obtain concentrations ranged within $5-100 \mathrm{mg} / \mathrm{L}$.

2.4. Batch Adsorption Experiments. The batch adsorption experiments were performed within a series of $30 \mathrm{mg}$ adsorbents mixed in range of $30-300 \mathrm{~mL}$ aqueous solution containing metallic $\operatorname{As}(\mathrm{V})$ ions at various concentrations ranged from 15 to $600 \mathrm{mg} / \mathrm{L}$. The suspension containing the adsorbents and $\operatorname{As}(\mathrm{V})$ ions was shaken constantly until reaching to equilibrium state. All the tests were performed at $25^{\circ} \mathrm{C}$ and $120 \mathrm{rpm}$ in a water bath.

2.5. As $(V)$ Concentration Measurement. The percentage removal (R\%) and the adsorption capacity $q_{e}(\mathrm{mg} / \mathrm{g})$ of adsorbents onto $\mathrm{As}(\mathrm{V})$ ions were calculated using equations (1) and (2) [23]:

$$
\begin{gathered}
R \%=\frac{C_{o}-C_{e}}{C_{o}} \times 100 \%, \\
q_{e}=\frac{\left(C_{o}-C_{e}\right) \times V}{m},
\end{gathered}
$$

where $C_{o}$ and $C_{e}$, respectively, represent the initial and final concentrations of $\mathrm{As}(\mathrm{V})$ ions $(\mathrm{mg} / \mathrm{L}), V$ is the volume of the solution (L), and $m$ is the weight of adsorbent (mg).

\section{Results}

\subsection{Sample Characterizations}

3.1.1. SEM Images and Textural Characteristics. The particle morphology and surface characteristics of FAC were investigated by SEM analysis. As can be seen in Figure 1, the iron oxide incorporated activated carbon (FAC) displayed a fairly homogeneous surface with numerous tiny cracking, pores, and channels which helped improve the porosity of the FAC [24]. According to Table 2, the specific surface area BET, total pore volume (TPV), and average porous diameter (APD) of FAC are $998 \mathrm{~m}^{2} \cdot \mathrm{g}^{-1}, 1.12$ $\mathrm{cm}^{3} \cdot \mathrm{g}^{-1}$, and $2.7 \mathrm{~nm}$, correspondingly. The formation of these pores and channels might be attributed to the carbonization of $\mathrm{BC}$, the modification with iron oxide nanoparticles, the melting, and cracking processes, which altogether contributed to improve the porosity of the products $[25,26]$.

3.1.2. TEM and XRD Studies. Figure 2(a) displays the TEM inner morphology of FAC composite with $200 \mathrm{~nm}$ scale bar. FAC has spherical shape, also describing the confirmation of uniform distribution of nano-sized $\mathrm{Fe}_{3} \mathrm{O}_{4}$ particles on AC surface. To analyze the crystal phase of FAC, the sample was determined by powder x-ray diffraction (XRD pattern) in the $2 \theta$ in area of $10-90^{\circ}$ at $25^{\circ} \mathrm{C}$ by using $\mathrm{Cu} \mathrm{k} \alpha(\lambda=1.54 \AA)$ radiation. The characteristic studies using XRD peak in Figure 2(b) indicate the peak of FAC composite. It confirms that the highest peaks of $\mathrm{Fe}_{3} \mathrm{O}_{4}$ at $2 \theta$ value of 30.2, 35.5, 43.4, 53.5, 57.1, and $62.9^{\circ}$ corresponded to (220), (311), (400), (422), (511), and (440) planes, compared with JCPDS No. 190629 [27].

3.1.3. Inorganic Elemental Analysis. The elemental component of OBC and FAC samples (wt\%) is shown in Table 3 . The heat treatment highly increased the carbon content of FAC [28]. The carbon content increased from $42 \%$ (in OBC) to $65 \%$ (in FAC) along with the oxygen content decrease from $49.34 \%$ to $28.76 \%$ indicating the effect of carbonization in UHPN. The decreased content of $\mathrm{H}, \mathrm{N}$, and $\mathrm{O}$ of FAC might be due to dehydration process and decarboxylation related with heat treatment at high temperature [29].

3.1.4. Determination of $p H_{p z c}$ Values. The $\mathrm{pH}_{\mathrm{pzc}}$ is an important factor in the adsorption process for the adsorbents as it indicates the acidic or alkaline characteristic and the 


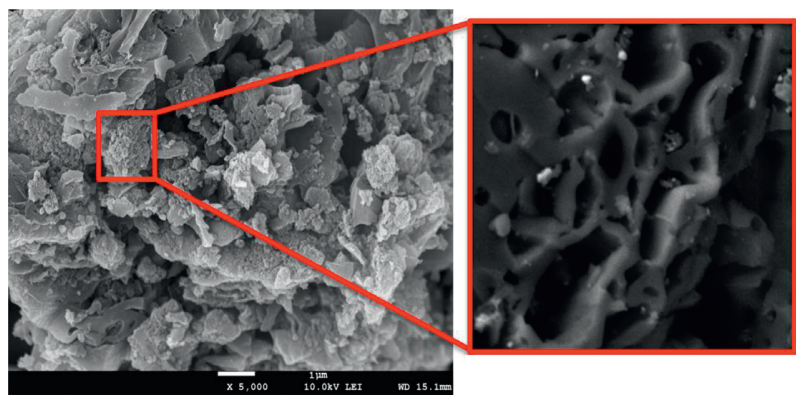

Figure 1: SEM images of FAC.

Table 2: The textural properties of FAC.

\begin{tabular}{lcc}
\hline BET surface area $\left(\mathrm{m}^{2} / \mathrm{g}\right)$ & TPV $\left(\mathrm{cm}^{3} / \mathrm{g}\right)$ & APD $(\mathrm{nm})$ \\
\hline 998 & 1.12 & 2.7 \\
\hline
\end{tabular}

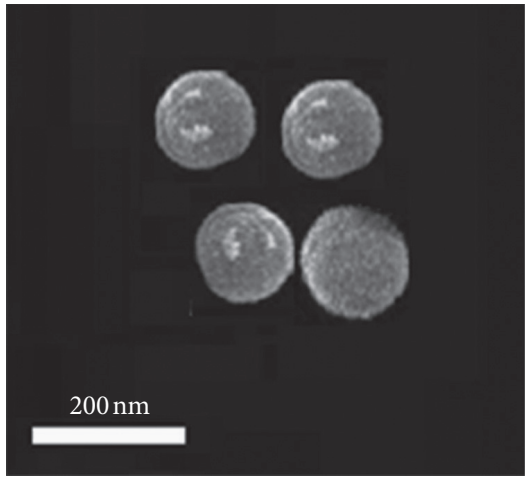

(a)

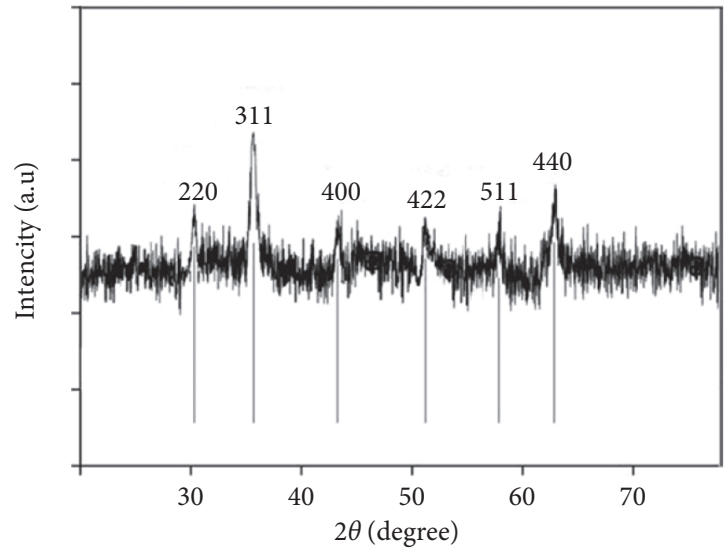

(b)

Figure 2: (a) TEM and (b) XRD results of FAC.

TABle 3: The elemental analysis (wt\%) of FAC and OBC products.

\begin{tabular}{lcccc}
\hline Samples & $(\%) \mathrm{C}$ & $(\%) \mathrm{H}$ & $(\%) \mathrm{N}$ & $(\%) \mathrm{O}$ \\
\hline FAC & 65.12 & 3.32 & 2.80 & 28.76 \\
OBC & 42.19 & 5.21 & 3.26 & 49.34 \\
\hline
\end{tabular}

net surface charge of materials in aqueous solutions. $\mathrm{pH}_{\mathrm{pzc}}$ is the $\mathrm{pH}$ at which the charge on the adsorbent surface is zero [30]. The $\mathrm{pH}_{\mathrm{pzc}}$ value of $\mathrm{OBC}$ and FAC was calculated at 3.22 and 6.18, respectively (Figure 3(a)). These values indicate the acidic nature of both samples that was desired for $A s(V)$ removal because the positive network of material surfaces is attractive to the anionic As complexes [31]. The shift in $\mathrm{pH}_{\mathrm{pzc}}$ of OBC and FAC from fairly strongly acidic 3.22 to nearly neutral 6.18 after modification implies the presence of alkaline functional groups (amino- $\mathrm{NH}_{2},-\mathrm{NH}-$ groups of AEAPTMS) on the surface of the material. The role of AEAPTMS in this study is to create firmly chemical connection between iron oxide and OBC as well as to help distribute these nanoparticles evenly on the material surface.

\subsection{Adsorption of $A s(V)$ Ions}

3.2.1. Influences of Solution $\mathrm{pH}$. The $\mathrm{pH}$ factor of a solution is one of the most important factors affecting the uptake of metal ions. Generally, the acidic environment ( $\mathrm{pH}$ range from 1 to 4 ) was the most beneficial condition for metallic anion uptake. Besides, $\mathrm{pH}$ above 8 might facilitate the precipitation of metal hydroxide. Therefore, in order to fully understand the effect of $\mathrm{pH}$ on the adsorption of $\mathrm{As}(\mathrm{V})$ onto $\mathrm{OBC}$ and FAC samples, experiments were conducted in a wide $\mathrm{pH}$ range of 2.0 to 9.0. As can be seen in Figure 3(b), both materials obtained the highest adsorption capacities $\left(q_{e}\right)$ of $\mathrm{As}(\mathrm{V})$ at the optimal $\mathrm{pH}$ ranged from 2 to 5 (acidic $\mathrm{pH}$ values), and $q_{e}$ decreased in the alkaline medium (when $\mathrm{pH}>6$ ). It might be due to the fact that in the strong alkaline 


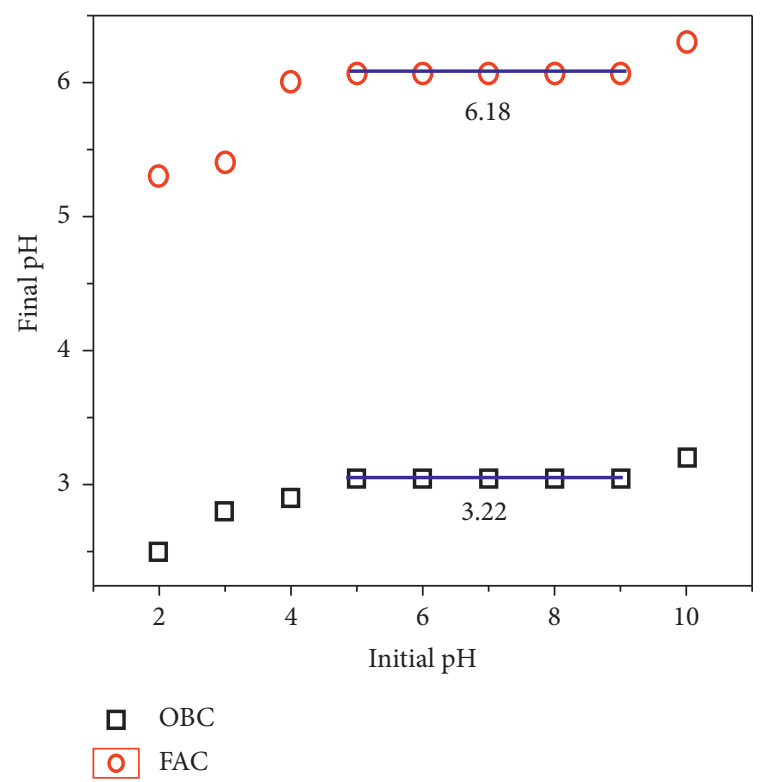

(a)

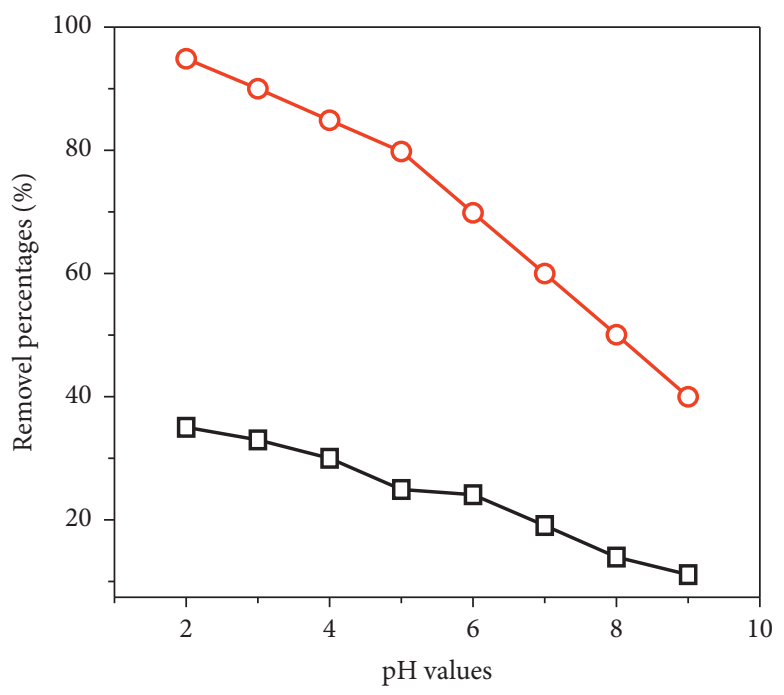

$\rightarrow \mathrm{OBC}$

(b)

Figure 3: (a) Plot of final $\mathrm{pH}$ vs. initial $\mathrm{pH}$, and (b) influences of $\mathrm{pH}$ on $\mathrm{As}(\mathrm{V})$ adsorption using $\mathrm{OBC}$ and $\mathrm{FAC}(\mathrm{m}$ adsorbents $=50 \mathrm{mg}$; $V$ $\operatorname{As}(\mathrm{V})$ solution $=50 \mathrm{~mL}$; time $=30 \mathrm{~min} ; C_{o}$ of $\mathrm{As}(\mathrm{V})=$ of $\left.100 \mathrm{mg} / \mathrm{L}\right)$.

conditions $(\mathrm{pH}>6)$ many $\mathrm{OH}^{-}$ions can compete with $\mathrm{As}(\mathrm{V})$ anions for the adsorption sites of the adsorbent surface.

Arsenic is mainly presented in water environment in the form of aqueous anions and neutral molecules including $\mathrm{HAsO}_{4}^{2-}$ (aq), $\mathrm{H}_{2} \mathrm{AsO}_{4}^{-}$(aq), and most likely partially as $\mathrm{H}_{3} \mathrm{AsO}_{4}(\mathrm{aq}), \mathrm{AsO}_{4}^{3-}$ (aq), and $\mathrm{H}_{2} \mathrm{AsO}_{3}{ }^{-}$(aq) in the $\mathrm{pH}$ ranged from 2 to 6 . Meanwhile, as confirmation from Figure 2, the zeta potentials of $\mathrm{OBC}$ and FAC were 3.22 and 6.18 , respectively. It means that while the solution $\mathrm{pH}<\mathrm{pH}_{\mathrm{pzc}}$, the surface charge of $\mathrm{OBC}$ and $\mathrm{FAC}$ is positive, and it is negative when $\mathrm{pH}>\mathrm{pH}_{\mathrm{pzc}}$. It is associated with the electrostatic interaction between surface sites and $\mathrm{As}(\mathrm{V})$ anion species in the solution, resulting in an enhanced adsorption capacity. For example, at the $\mathrm{pH}$ below 3, the surface charges of both $\mathrm{OBC}$ and FAC were positive, and the arsenic species existed in anion form, so it is reasonable to believe that the electrostatic interaction is the main mechanism in this process. If the $\mathrm{pH}$ of environmental solution is above 6 , the $\mathrm{OBC}$ and FAC surface is charged negatively, so that the electrical repulsion strongly prevents the interaction of the adsorbent and the pollutant.

3.2.2. Influence of Contact Time. The percentage removal of $\mathrm{As}(\mathrm{V})$ in the view of phase agitation time onto $\mathrm{OBC}$ and FAC is displayed in Figure 4(a). It might be investigated that the fast $\mathrm{As}(\mathrm{V})$ adsorption that occurred in the contact time ranged from 20 to $150 \mathrm{~min}$, and then adsorption process became slow and almost maintained equilibrium after $180 \mathrm{~min}$. It was because more active/available sites onto OBC and FAC were occupied by the adsorbed $\mathrm{As}(\mathrm{V})$ ions, and then the adsorption procedure was slowed down gradually.
Lengthening the reaction time does not increase the uptake efficiency since the desorption rate reaches equal value to the adsorption rate. The obtained results in the present work can be explained that at the beginning of adsorption process $\mathrm{As}(\mathrm{V})$ is adsorbed by the specific sites of FAC, while with increasing adsorption time these specific sites are saturated to some extent and the exchange sites on the surface of FAC are fully filled by As molecular, leading to a maintained adsorption efficiency after $180 \mathrm{~min}$.

3.2.3. Effect of Initial Concentration of $A s(V)$ Standard Solutions. The initial concentration $\left(C_{o}\right)$ is another significant aspect affecting the $\mathrm{As}(\mathrm{V})$ adsorption (Figure 4(b)). It was revealed that when $C_{o}$ increased, the $\mathrm{As}(\mathrm{V})$ removal percentage decreased dramatically, suggesting that $\mathrm{As}(\mathrm{V})$ adsorption is highly dependent on $C_{o}$. As further discussed in the upcoming section, the monolayer adsorption of FAC favors low concentration of As ions. Since the detected concentrations of $\mathrm{As}(\mathrm{V})$ in actual environment are usually in level of $\mu \mathrm{gL}^{-1}$, the uptake efficiency of $\mathrm{As}(\mathrm{V})$ onto $\mathrm{FAC}$ in actual application is predicted to be insignificantly different compared to laboratory conditions.

3.3. Adsorption Isotherms. Adsorption isotherms play an essential role in the understanding of the adsorbed amount of $\mathrm{As}(\mathrm{V})$ removed from the aqueous solution by unit mass of adsorbents. They also provide important factors to design the adsorption system in the field. The Langmuir equation is expressed as

$$
\frac{C_{e}}{q_{e}}=\frac{C_{e}}{q_{\max }}+\frac{1}{K_{L} \cdot q_{\max }}
$$




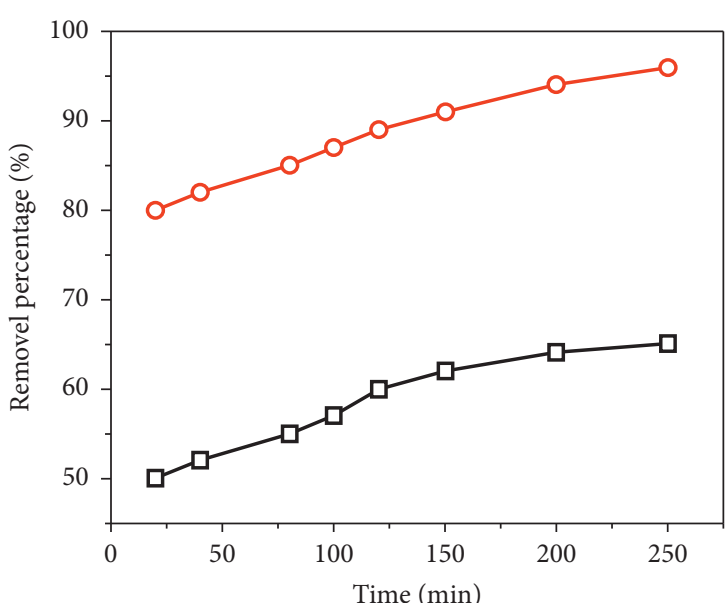

$\rightarrow$ OBC

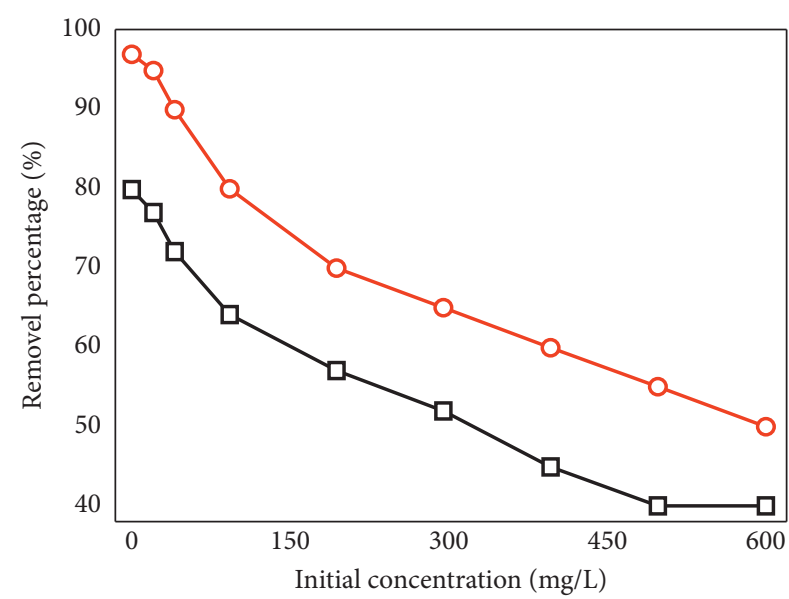

$\begin{array}{ll}-\square & \text { OBC } \\ -0- & \text { FAC }\end{array}$

(a)

(b)

FIgURe 4: Effect of (a) contact time and (b) initial concentration on the As(V) adsorption by OBC and FAC.

where $q_{e}$ is the amount of adsorbed $\mathrm{As}(\mathrm{V})$ ions per gram of adsorbent $(\mathrm{mg} / \mathrm{g}), q_{\max }$ is the maximum monolayer adsorption capacity $(\mathrm{mg} / \mathrm{g}), K_{\mathrm{L}}$ is the Langmuir constant related to the heat adsorption $(\mathrm{L} / \mathrm{mg})$, and $C_{e}$ is the supernatant equilibrium concentration $(\mathrm{mg} / \mathrm{L})$. The Freundlich equation can be expressed as

$$
\ln q_{e}=\ln K_{F}+\frac{1}{n} \ln C_{e},
$$

where $K_{F}$ is the Freundlich constant related with adsorption capacity $(\mathrm{mg} / \mathrm{g}$ ) and $n$ the adsorption intensity, which is indicative of the bonding energy between As ions and adsorbent. These plots of Langmuir and Freundlich models are illustrated in Figure 5(a), and their parameters are calculated and listed in Table 4.

Based on the data given in Figure 5 and Table 4, the As $(\mathrm{V})$ adsorption using FAC was well-fitted by the Langmuir model, better than that of Freundlich model. It suggested that the $\mathrm{As}(\mathrm{V})$ uptake behaviour on FAC is monolayer adsorption with homogeneous distribution of available networks on the surface of FAC. The value of $1 / n$ in Freundlich model below 1 suggests a favorable level of As adsorption by FAC [32]. The $K_{L}$ value of Langmuir model that ranged below 0.1 indicated a low surface energy in the adsorption process, thus revealing a stronger bonding force between $\mathrm{As}(\mathrm{V})$ ion and FAC $[33,34]$. As can be seen in the table, the maximum adsorption capacity $\left(Q_{\max }\right)$ of the FAC for $\mathrm{As}(\mathrm{V})$ ions, based on the Langmuir isotherm, was $32.57 \mathrm{mg} / \mathrm{g}$, which was higher than that of other previously reported materials (Table 5), proving that FAC might be used as a highly promising adsorbent for $\mathrm{As}(\mathrm{V})$ removal in wastewater treatment.

3.4. Adsorption Kinetics. The adsorption kinetics of $\mathrm{As}(\mathrm{V})$ adsorption onto FAC, the pseudo-first-order and pseudo-second-order kinetic models were applied to the experimental data and then, respectively, expressed by equations (5) and (6):

$$
\begin{aligned}
\log \left(q_{e}-q_{t}\right) & =\log q_{e}-\frac{k_{\mathrm{ad}}}{2.303} t, \\
\frac{t}{q_{t}} & =\frac{1}{h}+\frac{1}{q_{e}} t
\end{aligned}
$$

where $q_{e}$ and $q_{t}(\mathrm{mg} / \mathrm{g})$ represent the amount of the metal ions adsorbed at time $t(\mathrm{~min})$ and at equilibrium, respectively, $k_{\mathrm{ad}}$ is the rate constant of the adsorption $\left(\mathrm{min}^{-1}\right), h=$ $k q_{e}^{2}(\mathrm{mg} / \mathrm{g} / \mathrm{min})$ is the initial sorption rate as $t \longrightarrow 0$, and $k$ represents the rate constant of pseudo-second-order adsorption $(\mathrm{g} / \mathrm{mg} / \mathrm{min})$. These values were determined and are listed in Table 6. Two typical adsorption kinetic models, including pseudo-first-order and pseudo-second-order kinetic models, were applied to determine the kinetics of $\mathrm{As}(\mathrm{V})$ adsorption (Table 6). As can be seen in the table, the $q_{e}$, cal value of pseudo-first-order model was much lower than $q_{e \text {, exp }}$, suggesting that the arsenic ion adsorption was satisfactorily matched to the pseudo-second-order model, while the pseudo-first-order kinetic model did not fit well the data. Table 6 also indicates that the well-fitting of As(V) adsorption resulting from the pseudo-second-order model yielded very high determination coefficients $\left(R^{2}>0.99\right)$ as compared with the pseudo-first order plot. It also indicated that the chemisorption as the rate-limiting mechanism took place during the adsorption by FAC surface rather than physisorption $[2,5,19]$.

3.5. Proposal of Removal Mechanism. According to experiment data on the adsorption kinetics and isotherms in this study, the authors proposed the potential removal mechanism for the $\mathrm{As}(\mathrm{V})$ as in Figure 6. In aqueous solution, the outermost iron atoms in iron oxide nanoparticles attract 


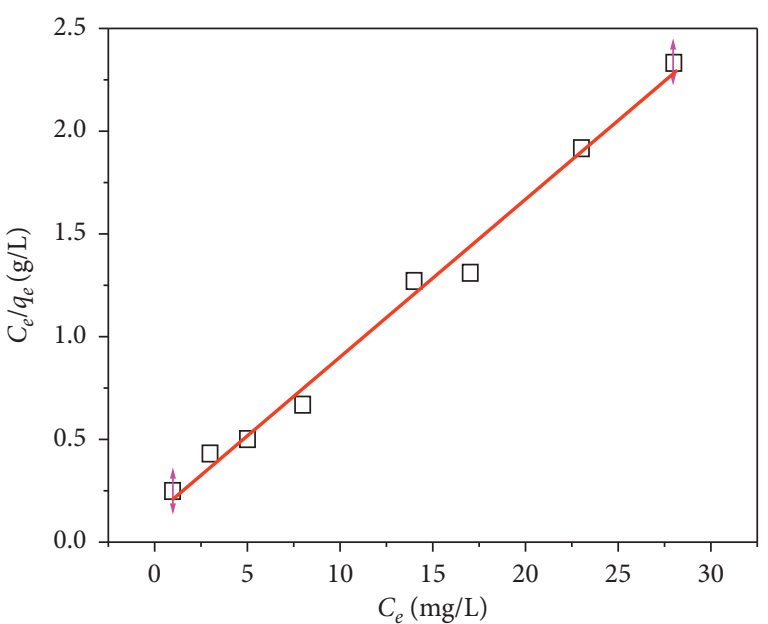

(a)

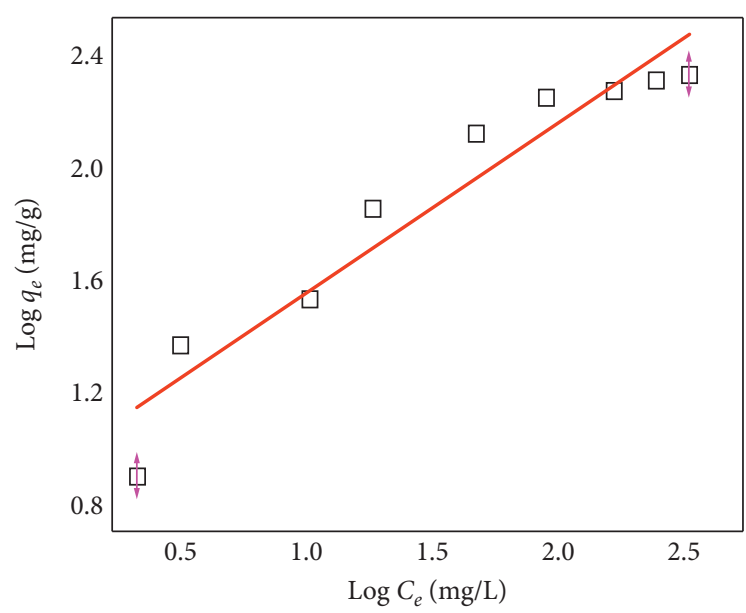

(b)

Figure 5: (a) Langmuir and (b) Freundlich plots on As(V) adsorption using FAC.

TABle 4: The Langmuir and Freundlich model parameters.

\begin{tabular}{ccccr}
\hline & Langmuir model & & \multicolumn{3}{c}{ Freundlich model } \\
$q_{\max }(\mathrm{mg} / \mathrm{g})$ & $K_{L}$ & $R^{2}$ & $K_{\mathrm{F}}$ & $1 / n$ \\
\hline 32.57 & 0.0766 & 0.98923 & 0.23 & 0.57 \\
\hline
\end{tabular}

TABLE 5: The comparison of adsorption capacities of As(V) onto FAC and other adsorbents

\begin{tabular}{lccccc}
\hline Adsorbents & Adsorption capacities $(\mathrm{mg} / \mathrm{g})$ & $\mathrm{pH}$ & BET surface area $\left(\mathrm{m}^{2} / \mathrm{g}\right)$ & Diameter $(\mathrm{nm})$ & References \\
\hline $\mathrm{Fe}_{3} \mathrm{O}_{4}$ particles & 16.6 & $5-7$ & 179 & 10 & {$[35]$} \\
Modified Fe/Mn-AC & 19.35 & $3-6$ & 973 & 111 & 2 \\
Akaganeite & 29.0 & 7 & 998 & $10-15$ & {$[36]$} \\
FAC & 32.57 & $2-5$ & 9.7 & This study \\
\hline
\end{tabular}

TABLE 6: Kinetic adsorption parameters for As(V) adsorption.

\begin{tabular}{lccccccc}
\hline $\begin{array}{l}q_{e, \exp } \\
(\mathrm{mg} / \mathrm{g})\end{array}$ & $k_{\mathrm{ad}}\left(\mathrm{min}^{-1}\right)$ & $q_{e, \text { cal }}(\mathrm{mg} / \mathrm{g})$ & $R^{2}$ & $k(\mathrm{~g} / \mathrm{mg} / \mathrm{min})$ & $q_{e, \text { cal }}(\mathrm{mg} / \mathrm{g})$ & $R^{2}$ & $h(\mathrm{mg} / \mathrm{g} / \mathrm{min})$ \\
\hline 32.57 & 0.0072 & 12.47 & 0.841 & 0.031 & 34.86 & 0.999 & 8.356 \\
\hline
\end{tabular}

Note: $q_{e, \text { cal }}$ calculated maximum adsorption capacity; $q_{e, \text { exp }}$ experimentally determined maximum adsorption capacity.

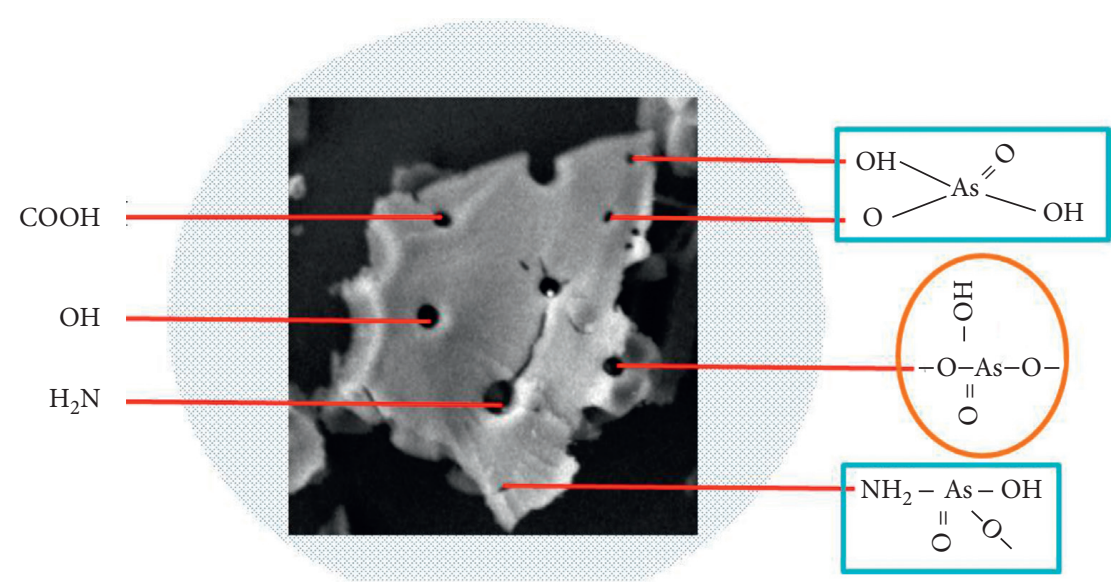

FIGURE 6: The proposed mechanism of As(V) adsorption by FAC. 
water molecules. After that, these water molecules are hydrolyzed to generate functional hydroxyl groups. Hence, the role of iron oxide nanoparticles is not only to increase the contacting surface area of the material but also to supplement numerous surface functional groups benefitting the removal. It is rational to believe that $\mathrm{As}^{+5}$ ions were mostly adsorbed on the surface of FAC via chemical interaction through the surface-bridging complexes by several functional groups onto FAC such as carboxyl $\left(\mathrm{R}-\mathrm{COOH}^{-}\right)$ groups, hydroxyl $\left(\mathrm{R}^{-\mathrm{OH}^{-}}\right)$groups, and amino $\left(-\mathrm{NH}_{2}\right)$ groups. In outer sphere complex of FAC, these surface functional groups are coordinated and bound directly to the structural $\mathrm{As}^{5+}$, to form the surface complexation of FAC$\mathrm{As}(\mathrm{V})$. Therefore, it was proposed to be a strong and easy adsorption of As $(\mathrm{V})$ by FAC. There are few literature reviews of $\mathrm{As}(\mathrm{V})$ adsorption behaviors onto the adsorbent materials by ligand-exchange mechanism, where the $\mathrm{As}^{+5}$ cation will be exchanged with the surface functional groups of $\mathrm{OH}$, $\mathrm{COOH}, \mathrm{OH}$, and $\mathrm{NH}_{2}$, which are directly incorporated to the FAC structural surface. That is the main reason for the higher removal rate of $\mathrm{As}(\mathrm{V})$ on the novel material FAC. Additionally, it is believed that the $\mathrm{As}(\mathrm{V})$ uptake onto FAC generates proton $\left(\mathrm{H}^{+}\right.$ions) to the solution, results in the $\mathrm{pH}$ value to strong acidic condition, and supports the adsorption equilibrium shift to the direction increasing removal efficiency. The mechanism totally agrees with observations in the $\mathrm{pH}$ investigation $[21,38]$.

\section{Conclusions and Discussion}

This work aimed to describe the facile synthesis of green bio-nanomaterial (FAC) from its precursor (BC from w.w) for $\mathrm{As}(\mathrm{V})$ adsorption. We figured out that the maximum adsorption capacity of FAC for $\mathrm{As}(\mathrm{V})$ was $32.57 \mathrm{mg} / \mathrm{g}$ in the views of adsorption kinetics and isotherms. The adsorption data demonstrated that the $\mathrm{As}(\mathrm{V})$ adsorption process can be matched by the pseudo-second-order kinetic equation and the adsorption isotherm was well-fitted to the Langmuir model. The higher adsorption capacity of FAC for $\mathrm{As}(\mathrm{V})$ removal was also compared with the previously reported literatures. The effective studies of $\mathrm{pH}$, time, and initial concentration confirmed that $\mathrm{As}(\mathrm{V})$ adsorption was favorably affected by the surface-bridging complexes, while As $(\mathrm{V})$ was removed, associated with the ligand-exchange and electrostatic interaction.

\section{Data Availability}

All the data and supporting materials are included within the article.

\section{Conflicts of Interest}

The authors declare that there are no conflicts of interest regarding the publication of this article.

\section{References}

[1] J. Parascandola, King of Poisons: A History of Arsenic, Potomac Books, Inc., Sterling, VA, USA, 2012.
[2] M. H. Nguyen, Q. A. Hoang, L. A. Nguyen et al., "An exposure assessment of arsenic and other trace elements in $\mathrm{Ha} \mathrm{Nam}$ province, Northern Vietnam," International Journal of Analytical Chemistry, vol. 2019, Article ID 5037532, 8 pages, 2019.

[3] T. D. Pham, H. H. Nguyen, N. V. Nguyen et al., "Adsorptive removal of copper by using surfactant modified laterite soil," Journal of Chemistry, vol. 2017, Article ID 1986071, 10 pages, 2017.

[4] T. M. T. Nguyen, T. P. T. Do, T. S. Hoang et al., “Adsorption of anionic surfactants onto alumina: characteristics, mechanisms, and application for heavy metal removal," International Journal of Polymer Science, vol. 2018, Article ID 2830286, 11 pages, 2018.

[5] T. D. Nguyen, H. B. Le, T. O. Dong, and T. D. Pham, "Determination of fluoroquinolones in pharmaceutical formulations by extractive spectrophotometric methods using ion-pair complex formation with bromothymol blue," Journal of Analytical Methods in Chemistry, vol. 2018, Article ID 8436948, 11 pages, 2018.

[6] T. D. Pham, M. Kobayashi, and Y. Adachi, "Adsorption of polyanion onto large alpha alumina beads with variably charged surface," Advances in Physical Chemistry, vol. 2014, Article ID 460942, 9 pages, 2014.

[7] H. T. Ha, N. T. Huong, L. L. Dan, N. D. Tung, V. B. Trung, and T. D. Minh, "Removal of heavy metal ion using polymer-functionalized activated carbon: aspects of environmental economic and chemistry education," Journal of Analytical Methods in Chemistry, vol. 2020, Article ID 8887488, 13 pages, 2020.

[8] H. T. Ha, N. T. Huong, B. K. Lee et al., "Ternary magnetic polymer cross-coupled in [ $\gamma$-APTES]-dispersion to remove azole compound: economic research and educational policy management," Research on Chemical Intermediates, vol. 46, pp. 1-26, 2020.

[9] J. S. Uppal, Q. Zheng, and X. C. Le, "Arsenic in drinking water-recent examples and updates from Southeast Asia," Current Opinion in Environmental Science \& Health, vol. 7, pp. 126-135, 2019.

[10] A. Buccolieri, A. Serra, G. Maruccio et al., "Synthesis and characterization of mixed iron-manganese oxide nanoparticles and their application for efficient nickel ion removal from aqueous samples," Journal of Analytical Methods in Chemistry, vol. 2017, Article ID 9476065, 9 pages, 2017.

[11] H. T. Ha, N. T. Huong, T. D. Minh et al., "Feasibility study of Cd (II) adsorption by a novel magnetic-graphene oxide assisted with polymer from solution," Journal of Environmental Engineering, vol. 146, no. 7, Article ID 04020060, 2020.

[12] N. T. Hanh, N. Le Minh Tri, D. Van Thuan et al., "Monocrotophos pesticide effectively removed by novel visible light driven $\mathrm{Cu}$ doped $\mathrm{ZnO}$ photocatalyst," Journal of Photochemistry and Photobiology A: Chemistry, vol. 382, Article ID 111923, 2019.

[13] M.-T. Nguyen-Le, B.-K. Lee, and D.-M. Tran, "EDTA-Na ${ }_{2}$ assisted synthesis of rod-like titanate- $\mathrm{TiO}_{2}$ composite architectures with enhanced visible-light-driven properties," Journal of Industrial and Engineering Chemistry, vol. 56, pp. 225-233, 2017.

[14] N. N. Dao, N. V. N. Mai, D. T. Doan et al., "Effect factors of synthesizing structured nano iron-manganese oxide particles by citric acid and study on arsenic adsorption," Vietnam Journal of Chemistry, vol. 55, pp. 336-340, 2017. 
[15] Y. Yu, J. Addai-Mensah, and D. Losic, "Functionalized diatom silica microparticles for removal of mercury ions," Science and Technology of Advanced Materials, vol. 13, 2012.

[16] H. Wi, H. Kim, D. Oh, S. Bae, and Y. Hwang, "Surface modification of poly(vinyl alcohol) sponge by acrylic acid to immobilize Prussian blue for selective adsorption of aqueous cesium," Chemosphere, vol. 226, pp. 173-182, 2019.

[17] Y. Mamindy-Pajany, C. Hurel, N. Marmier, and M. Roméo, "Arsenic adsorption onto hematite and goethite," Comptes Rendus Chimie, vol. 12, no. 8, pp. 876-881, 2009.

[18] M. E. Pena, G. P. Korfiatis, M. Patel, L. Lippincott, and X. Meng, "Adsorption of As(V) and As(III) by nanocrystalline titanium dioxide," Water Research, vol. 39, no. 11, pp. 2327-2337, 2005.

[19] M. H. Nguyen, T. D. Pham, T. L. Nguyen et al., "Speciation analysis of arsenic compounds by HPLC-ICP-MS: application for human serum and urine," Journal of Analytical Methods in Chemistry, vol. 2018, Article ID 9462019, 8 pages, 2018.

[20] N. Nematidil, M. Sadeghi, S. Nezami, and H. Sadeghi, "Synthesis and characterization of Schiff-base based chitosan-g-glutaraldehyde/NaMMTNPs-APTES for removal $\mathrm{Pb}^{2+}$ and $\mathrm{Hg}^{2+}$ ions," Carbohydrate Polymers, vol. 222, Article ID 114971, 2019.

[21] H. Ha, T. Minh, H. Nguyet, and A. Sharma, "Ampicillin adsorption onto amine-functionalized magnetic graphene oxide: synthesis, characterization and removal mechanism," Korean Journal of Chemical Engineering, vol. 38, no. 1, pp. 22-31, 2021.

[22] G. O. El-Sayed, M. M. Yehia, and A. A. Asaad, "Assessment of activated carbon prepared from corncob by chemical activation with phosphoric acid," Water Resources and Industry, vol. 7, pp. 66-75, 2014

[23] T. D. Minh, B.-K. Lee, and P. H. Linh, "Highly efficient removal of emerging organic compound 1,3-benzodiazole using novel triangular coordination of magnetic-polymer nanohybrid $\left[\mathrm{C}_{2} \mathrm{H}_{5} \mathrm{OH}\right]$-MNPs@y-APTES@GO,” Research on Chemical Intermediates, vol. 44, no. 11, pp. 6515-6536, 2018.

[24] W. Xiong, J. Tong, Z. Yang et al., "Adsorption of phosphate from aqueous solution using iron-zirconium modified activated carbon nanofiber: performance and mechanism," Journal of Colloid and Interface Science, vol. 493, pp. 17-23, 2017.

[25] H. Gong, Z. Chen, Y. Fan, M. Zhang, W. Wu, and W. Wang, "Surface modification of activated carbon for siloxane adsorption," Renewable Energy, vol. 83, pp. 144-150, 2015.

[26] D. Zhang, P. Huo, and W. Liu, "Behavior of phenol adsorption on thermal modified activated carbon," Chinese Journal of Chemical Engineering, vol. 24, 2015.

[27] B. Y. Yu and S.-Y. Kwak, "Assembly of magnetite nanocrystals into spherical mesoporous aggregates with a 3-D wormhole-like pore structure," Journal of Materials Chemistry, vol. 20, no. 38, pp. 8320-8328, 2010.

[28] C.-H. Hsu, W.-C. Huang, Y.-P. Lee, and W.-Y. Ho, "Effect of nitrogen atmosphere heat treatment on structure and wear behavior of CrAlSiN nanocomposite film," Surface and Coatings Technology, vol. 320, pp. 230-234, 2017.

[29] E. M. Batista, J. Shultz, T. T. Matos et al., "Effect of surface and porosity of biochar on water holding capacity aiming indirectly at preservation of the amazon biome," Scientific Reports, vol. 8, no. 1, Article ID 10677, 2018.

[30] S. Joshi and B. P. Pokharel, "Preparation and characterization of activated carbon from lapsi (Choerospondias axillaris) seed stone by chemical activation with potassium hydroxide,"
Journal of the Institute of Engineering, vol. 9, no. 1, pp. 79-88, 2014.

[31] E. Tombácz, Z. Libor, E. Illés, A. Majzik, and E. Klumpp, "The role of reactive surface sites and complexation by humic acids in the interaction of clay mineral and iron oxide particles," Organic Geochemistry, vol. 35, no. 3, pp. 257-267, 2004.

[32] R.-L. Tseng and F.-C. Wu, "Inferring the favorable adsorption level and the concurrent multi-stage process with the Freundlich constant," Journal of Hazardous Materials, vol. 155, no. 1-2, pp. 277-287, 2008.

[33] S. Sajidu, E. Henry, I. Persson, W. Masamba, and D. Kayambazinthu, " $\mathrm{pH}$ dependence of sorption of $\mathrm{Cd}^{2+}$, $\mathrm{Zn}^{2+}, \mathrm{Cu}^{2+}$ and $\mathrm{Cr}^{3+}$ on crude water and sodium chloride extracts of Moringa stenopetala and Moringa oleifera,/i," African Journal of Biotechnology, vol. 5, no. 23, 2006.

[34] F. Chigondo, T. Nyambuya, and M. Chigondo, "Removal of zinc(II) ions from aqueous solution using msasa tree (Brachystegia spiciformis) leaf powder: equilibrium studies," Journal of Asian Scientific Research, vol. 3, no. 2, p. 140, 2013.

[35] G. Gallios, A. Tolkou, I. Katsoyiannis, K. Stefusova, M. Vaclavikova, and E. Deliyanni, "Adsorption of arsenate by nano scaled activated carbon modified by iron and manganese oxides," Sustainability, vol. 9, no. 10, p. 1684, 2017.

[36] Y.-X. Zhang and Y. Jia, "A facile solution approach for the synthesis of akaganéite $(\beta-\mathrm{FeOOH})$ nanorods and their ion-exchange mechanism toward As(V) ions," Applied Surface Science, vol. 290, pp. 102-106, 2014.

[37] T. D. Minh and B.-K. Lee, "Ternary cross-coupled nanohybrid for high-efficiency $1 \mathrm{H}$-benzo[d]imidazole chemisorption," Environmental Science and Pollution Research, vol. 25, no. 22, pp. 21901-21914, 2018.

[38] L. Feng, M. Cao, X. Ma, Y. Zhu, and C. Hu, "Superparamagnetic high-surface-area $\mathrm{Fe}_{3} \mathrm{O}_{4}$ nanoparticles as adsorbents for arsenic removal," Journal of Hazardous Materials, vol. 217, pp. 439-446, 2012. 